\title{
Ptolemaic Mummy Stuffings: \\ An Intriguing Ptolemaic Scholar's Text in the Yale Collection (P.CtYBR 5018)
}

\author{
William A. Johnson*
}

\begin{abstract}
Beinecke papyrus PCtYBR inv. 5018 is a fragment that has the appearance of a Ptolemaic bookroll, but whose contents are more that of a scholar's notes. The papyrus consists of a series of well-defined entries, each with three elements: (1) an ordinal number (surviving are "10th" through "15th"); (2) the lemma, no more than a phrase, apparently excerpted from an unknown prose text; (3) literary examples or verbatim quotations, presumably intended to illustrate the content of the lemma. Quoted are a passage from Odyssey 11 and two trimeter lines from an unknown tragedy or tragedies. The contents of the prose text from which the lemmata derive is not clear, but appears to regard poetics or poetic composition.
\end{abstract}

Keywords: literary papyri, Ptolemaic bookroll, Odyssey, tragedy, excerpting, poetics

DOI 10.1515/apf-2016-0001

P.CtYBR inv. 5018

Late $3^{\text {rd }} /$ early $2^{\text {nd }} \mathrm{c} . \mathrm{BC}$

dimensions: $19.3 \times 21.5 \mathrm{~cm}$

roll height: $21.5 \mathrm{~cm}$ (possibly complete)

column height: ii $17.3 \mathrm{~cm}$, Class II

upper margin: $2.2 \mathrm{~cm}$ (possibly complete)

lower margin: $2.0 \mathrm{~cm}$ (possibly complete)

column-to-column width: ii $7.2 \mathrm{~cm}$, iii $7.3 \mathrm{~cm}$

column width: ii $6.4 \mathrm{~cm}$, iii $6.4 \mathrm{~cm}$, Class II

* Corresponding author: William A. Johnson, Duke University, 233 Allen Building, Box 90103, Durham, NC 27708, USA, <william.johnson@duke.edu> 
intercolumn: $0.7-1.2 \mathrm{~cm}$, Class I

letter height: $3.0 \mathrm{~mm}$

letter width: $3.0 \mathrm{~mm}$ (average)

leading: $0.7 \mathrm{~cm}$

kollesis: at roughly 6-6.5 cm from left edge, 3-3.5 cm from left of col. ii, with an overlap of ca. $1.7 \mathrm{~cm}$; maximum extent of rightmost kollema ca. $13 \mathrm{~cm}$ (not complete)

In 1998 Yale's Beinecke Library acquired a small group of ancient textual artefacts from Gallery Nefer, Zurich. The group, said to come from a private collector (unnamed) who had acquired the materials prior to 1972, is various; the catalogued items consist of one unrolled lead tablet (P.CtYBR inv. 5056), ten Greek Ptolemaic papyri (P.CtYBR inv. 5018, 5019, 5043, 5044, 5058, 5059, 5060, 5061, 5062, 5063), and one Coptic text from late antiquity (P.CtYBR inv. 5057). The whole of the acquisition is catalogued by the Beinecke as "1998b".

The ten Ptolemaic pieces are of particular interest, since they are the larger fragments from three wads of papyrus, which were represented by the dealer as constituting the stuffing for the stomach cavity of a mummified animal. The wads had the appearance of scrap pieces that had been gathered together and then crumpled lightly by a hand (as one would expect for stuffing), but were also hard and brittle, as though exposed to gesso and some kind of resin; ${ }^{1}$ several of the papyri themselves show dark stains, and all have on the surface remnants of a white wash that will be calcium carbonate residue from gesso. ${ }^{2}$ Prior to purchase, the dealer supplied the then curator of the Beinecke (R.G. Babcock) a photograph of the three wads, and one of those had visible the lower central area of what is now catalogued as 5018, including the entirety of the bottom part of column ii; this suggests that the wads, approximately equal in size, were something like $10 \mathrm{~cm}$ in diameter. Unfortunately, that photograph (which I inspected and took notes on at the time) is no longer part of the Beinecke files. ${ }^{3}$

From the three wads came a number of small scraps in demotic and Greek that remain uncatalogued, along with the ten Greek Ptolemaic

${ }^{1}$ The wads were described as "dried and hard like paper mache" before being humidified and flattened. Personal email communication, R.G. Babcock, 1998.

${ }^{2}$ On calcium carbonate see Jaakko Frösén, "Conservation of Ancient Papyrus Materials," in Roger Bagnall, ed., The Oxford Handbook of Papyrology (Oxford 2009) 87.

${ }^{3}$ The photograph was dated March 1, 1987 (my personal notes, 1998). When the three wads arrived at Beinecke, no photographs were taken until after the papyri had been flattened. 
pieces listed above. The nine aside from 5018 include a fragment of comedy (5019), a fragment of a grammarian's text (5043), and seven documents; the publication of these nine is forthcoming. Three of the documents $(5058,5059,5062)$ mention the Herakleopolite nome or towns therein, including Ankyronpolis (el-Hibeh), and one (5062) the Arsinoite nome. ${ }^{4}$ One document (5063) carries a date in the $11^{\text {th }}$ year of the King's reign. Given the palaeography, the king will be Ptolemy IV Philopator or Ptolemy V Epiphanes, and the date either 209 or $192 \mathrm{BC}$. But the relationship of these papyri to 5018 is only that they came from the same three wads of scrap paper. A tighter link unfortunately cannot be drawn: it is uncertain which papyri belong to which wad, and the seller's story that the three wads came from one animal, though not in itself implausible, is also uncertain.

The four extant columns of 5018, of which the two middle are mostly complete, have the mise en page of a Ptolemaic literary bookroll. Formal features are exactly what one would expect: the Class II column width seems to have been the dominant width for bookrolls in Ptolemaic times; similarly for the narrow Class I intercolumn and the Class II height. ${ }^{5}$ The short roll height of ca. $21.5 \mathrm{~cm}$ accords exactly with measurements of several Ptolemaic bookrolls. ${ }^{6}$ The script is a good-looking if somewhat informal Ptolemaic book hand. Notional divisions in the text are marked with paragraphus and a blank space, a common Ptolemaic practice. ${ }^{7}$ Adscript is written, as we expect. ${ }^{8}$ The somewhat ragged right margin, and the column leaning according to the dictate of Maas' Law, is also typical of Ptolemaic bookrolls. ${ }^{9}$ Nothing in the look or feel, then, signals anything other than a literary prose text of the era.

\footnotetext{
${ }^{4}$ The locations suggest the possibility that the mummified animal was a crocodile.

${ }^{5}$ Column width: William A. Johnson, Bookrolls and Scribes in Oxyrhynchus (Toronto 2004) 108; cf. Alain Blanchard, "Les papyrus littéraires grecs extraits de cartonnages: études de bibliologie" in M. Maniaci and P.F. Munafò, edd., Ancient and Medieval Book Materials and Techniques (Città del Vaticano 1993), 35. Intercolumn: Johnson, 113, cf. Blanchard, 35. Column height: Johnson, 124, Blanchard, 31-2.

${ }^{6}$ Listed in Blanchard, Papyrus littéraires grecs 32; cf. Johnson, Bookrolls and Scribes 142.

${ }^{7}$ William A. Johnson, "The Function of the Paragraphus in Greek Literary Prose Texts," ZPE 100 (1994) 65-68.

${ }^{8}$ Willy Clarysse, "Notes on the use of the iota adscript in the third century B.C.," $C E$ 51 (1976) 150-166.

${ }^{9}$ Johnson, Bookrolls and Scribes, 92.
} 
The content is, however, more perplexing. The text is not running prose, but a set of entries with a consistent structure. Each entry in the text has three elements.

1. An ordinal number. Extant in whole or part are Tenth, Eleventh, Twelfth, Thirteenth, Fourteenth, Fifteenth. The adjective assumes an unspecified noun in the neuter. Immediately following this (without punctuation) is:

2. A lemma, no more than a phrase, that appears to be a short quotation from a prose text otherwise unknown. More on the nature of this text below. The end of the lemma is marked with paragraphus and space.

3. A comment, which thrice begins with $\kappa \alpha \theta \alpha \dot{\pi} \varepsilon \rho$, four times with oiov, and (so far as one can tell) is always an example drawn from a literary text, or a quotation verbatim. The examples mention Odysseus by name twice (Twelfth: ii.25; Thirteenth: iii.12), include a three-line quotation from Odyssey book 11 (Twelfth: iii.4ff.), and twice mention "the poet" in contexts that assure us Homer is meant (Twelfth: ii. 24, Thirteenth: iii. 11f.); but the other pair of verses quoted, fully legible, are in trimeters (Fourteenth: iii.21-24), and though the first appears to have Menelaus and Helen in view, the second seems to reference something outside of the epic cycle. The comment given under the Eleventh, at ii.18-22, seems to refer to neither Homer nor the story of Troy. The end of each comment is marked by paragraphus with space. For the quotations, verse ends are also marked by space, and in the case of the trimeters, the space is accompanied by a paragraphus, probably to clarify that the verses are not continuous but from different contexts or plays (see commentary ad loc.).

Most striking in the structure of the entries is the use of ordinal numbers: Tenth, Eleventh, etc., all adjectives in the neuter. In very broad terms, the text seems reminiscent of Aristotlean problemata. But in that tradition, one poses a question or sets up a statement or quote which is then explained or interrogated. The "problem" can receive an ordinal number, as here. The subject nouns for such lists can be various, including

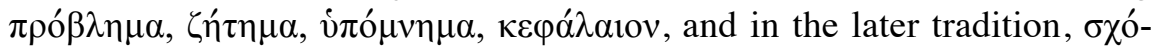
$\lambda$ tov. Here, however, the ordinated item seems to be a short quote (i.e. a lemma) followed by a "comment" that is not an explanation but a quotation or literary example. Since the writer uses heavily the characteristic scholiastic expressions $\kappa \alpha \theta \alpha \dot{\alpha} \varepsilon \rho$ (“just as") and oîo ("as, for 
example,"), it is attractive to link this text to the scholiastic or hypomnema traditions, but in these the comments are more self-evidently explanatory and do not contain the ordinals familiar from the "Problems" tradition. What this text is not: not a set of problêmata, not a mythological commentary, not a lexical commentary, nor metrical, nor philological.

Among several tantalizing features in our papyrus, the most fascinating is the target text that provides the source of the quotations and on which the comments/examples hang. The nature of that text - prose and otherwise unknown - is difficult to discern, yet we can isolate some defining characteristics. In the examples that can be read with confidence, the lemma is often written in moralistic, rhetorical terms:

Eleventh: "To lead towards the critical points or what is needed"

Twelfth: "One should make great what has been deemed the lesser"

Thirteenth: "To conceal and pass by in silence"

Fourteenth: "What is worthy and not worthy"

Fifteenth: "What is distinctive"

Moreover, all but the Fifteenth have contrasting pairs that add up to a thought, but the pairing is subtle, with only the Fourteenth a simple opposition:

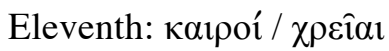

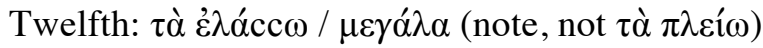

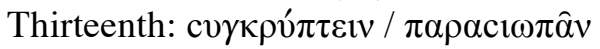

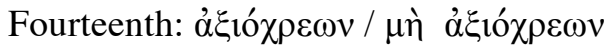

The target text seems to be some sort of text of instruction, or at least the lemmata and comments seem deployed with that in mind. As Nita Krevans has remarked, ${ }^{10}$ if the papyrus were later, one might want to see in it the exercises of the rhetorical schools, such that the tag line (what I am calling the lemma) is the topic of a speech or speech component, and the comments - all literary examples - ready-to-use material for fleshing out and ornamenting the rhetorical argument. But the ordinated lemmata do not sound like topics. Rather, they sound like precepts or principles excerpted from a running text, and these principles, if I am reading this rightly, seem to refer to what the poet should or does do, followed then by examples from the realm of epic and drama. Agamemnon's rejection of Chryses is given as an example of how a poet brings the reader to a criti-

\footnotetext{
${ }^{10}$ At the North American Papyrology Seminar in Ann Arbor, Michigan (May 2015).
} 
cal turning point; the transformation of Odysseus from disguised pastoral stranger to King is given as an example of how the poet uplifts to greatness what had seemed inferior. The mention of Agamemnon's military expedition for the sake of a woman is given as an example of how "what is worthy" is introduced into a work. This is not to downplay the difficulties in explaining how the examples relate to the lemmata - much remains confusing or uncertain - but it seems fairly clear that the overall subject matter is what the poet does to achieve a certain effect.

The target text from which these excerpts are taken seems, then, to be a prose treatise on poetics or poetic composition. That treatise, to judge from the lemmata, has at least some subtlety in its rhetoric of pairing and contrast. There is little more that can reliably be said, except that the literary examples are most probably taken from that same treatise, since without further context they seem too loosely bound to the lemmata to be exemplifications culled by the excerpter to fit the lemmata. I take the contents, then, to be some sort of exercise in excerpting, and the excerpter will be in some sense a "scholar" (i.e. someone with a deep interest in literary matters, including composition), but the exact purpose or use remains obscure.

Other mysteries remain. Why is this collection of excerpts and exempla copied in the manner of a bookroll? As indicated, the papyrus in format and convention suggests a literary book, not the private notes of a reader. And the numbers, what do they refer to? The lemmata are too small in scope for these to be book numbers ( $\tau$ ò $\beta \imath \beta \lambda$ íov); do they enumerate topics

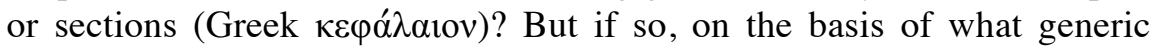
convention or tradition?

Ptolemaic book hands cannot be dated with precision on palaeographical grounds, but the hand here shows affinities with the groups in Hellenistic Bookhands \#33-37, pp. 63-68, cf. esp. \#36 (P.Dublin TC 274, late $3^{\text {rd }}$ c. BC) and \#37 (P.Vindob. G 40612, 213 BC), and \#49-53, pp. 84-89, cf. esp. \#53 (P. Dion. 25, probably early $2^{\text {nd }}$ c. BC). ${ }^{11}$ The hand is small and neat, with a strong but not strict tendency towards bilinearity. Much of the time, $\varepsilon \theta$ o c are near full height; o c fairly often and $\varepsilon$ only occasionally are written small and high; $\rho \mathrm{i} v$ and sometimes $\tau$ slightly break the notional base line; $\alpha$ is consistently angular; tiny serifs or hooks can appear at base of $v \rho \tau$, also on left hasta of $\kappa \pi$, and sometimes $v \eta$. A date of the late third or early second centuries $\mathrm{BC}$ can be assigned with rea-

\footnotetext{
${ }^{11}$ Guglielmo Cavallo and Herwig Maehler, Hellenistic Bookhands (Berlin, 2008).
} 
sonable confidence on paleographical grounds; as mentioned at the front, a documentary text that may be from the same cache of scrap paper is dated to 209/192. A contemporary corrector, probably the same hand, makes two additions above the line, at iii.24 and iii.26.

The text is written along the fibers. The back has indecipherable writing written the other way up and across the fibers, apparently a list in demotic with, at the far right edge, a few letters of the left edge of a column in Greek. The papyrus is heavily stained on back and front with some sort of resin, has remains of gesso (calcium carbonate) on its surface, and the ink has bled or transferred in places, making the text in part challenging or even impossible to read. The transcription relies both on the visible light spectrum, using autopsic inspection and computer imaging enhancements, and on an infra-red photograph. Following the practice adopted in Johnson, Bookrolls and Scribes, I transcribe what I take to be deliberate punctuation spaces with the siglum .

The papyrus contains two new verses from tragedy (iii.21-24) and a quote from the Odyssey (11.549-551) that includes a minor variant known only from thin attestation in the medieval tradition.

\section{Transcription}

Fr. a

Col. i

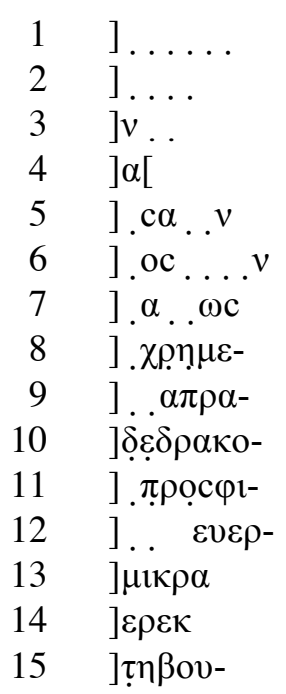


$16] \chi \chi \alpha$

17 ]oic

$18] \pi \alpha$

19 ]vло

$20 \quad] \varphi \mathrm{r}$

$21] \tau \omega \iota$

$22] v$

23 ] $\alpha v$

24 lac.

25 lac.

26 lac.

Col. ii

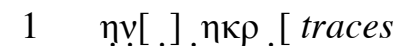

$2 \delta \varepsilon \kappa \alpha \tau[$ traces

3 a. [traces

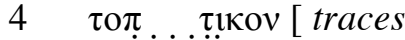

5 [traces c. 14 ]ĉ̣v olov

$6 \quad \varepsilon \alpha v \delta \varepsilon \pi \varepsilon \ldots . . .0 .0 \% \alpha \nu$

$7 \quad \eta \lambda \alpha \tau \tau \omega \ldots \ldots \kappa \kappa c$

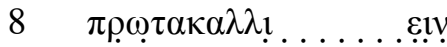

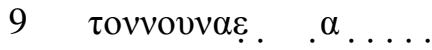

$10 \quad \alpha v \tau \alpha \omega[$ traces

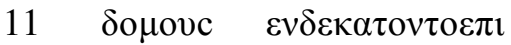

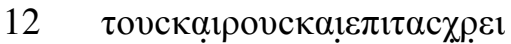

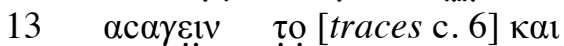

14 рovcaọove $\pi \lambda[$ traces

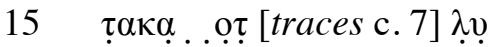

$16 \tau \rho \alpha \kappa \alpha \tau \alpha \beta \alpha \lambda \lambda \varepsilon ! \varphi$

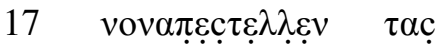

$18 \delta \varepsilon \chi \rho \varepsilon เ \alpha[\ldots .$.$] otov. . . \delta \delta \alpha$

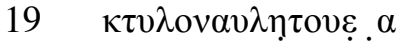

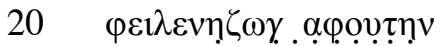

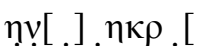

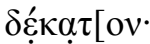

$\alpha .[$

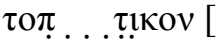

]c̣vv oîov

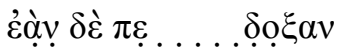

$\eta \lambda \alpha \tau \tau \omega \ldots . . . . \kappa \alpha c$

$\pi \rho \hat{\omega} \tau \alpha \kappa \alpha \lambda \lambda \iota . . . . \varepsilon ! \varphi$

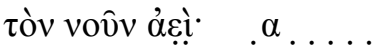

$\alpha \cup \tau \alpha \omega[$

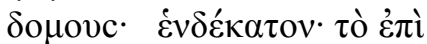

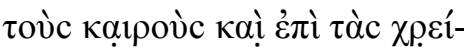

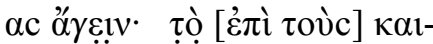

poúc oî́o $\varepsilon \pi \lambda[$

$\tau \alpha \kappa \alpha$. . ơ] ] ] ]ứ-

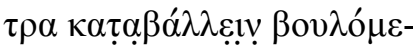

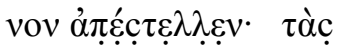

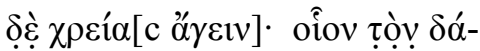

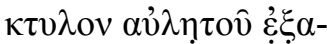

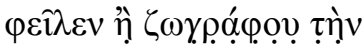




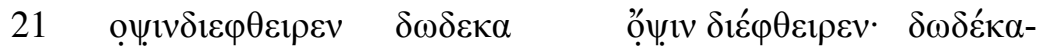

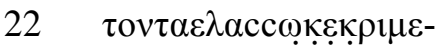

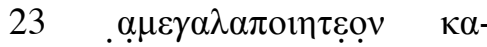

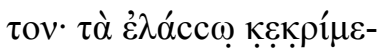
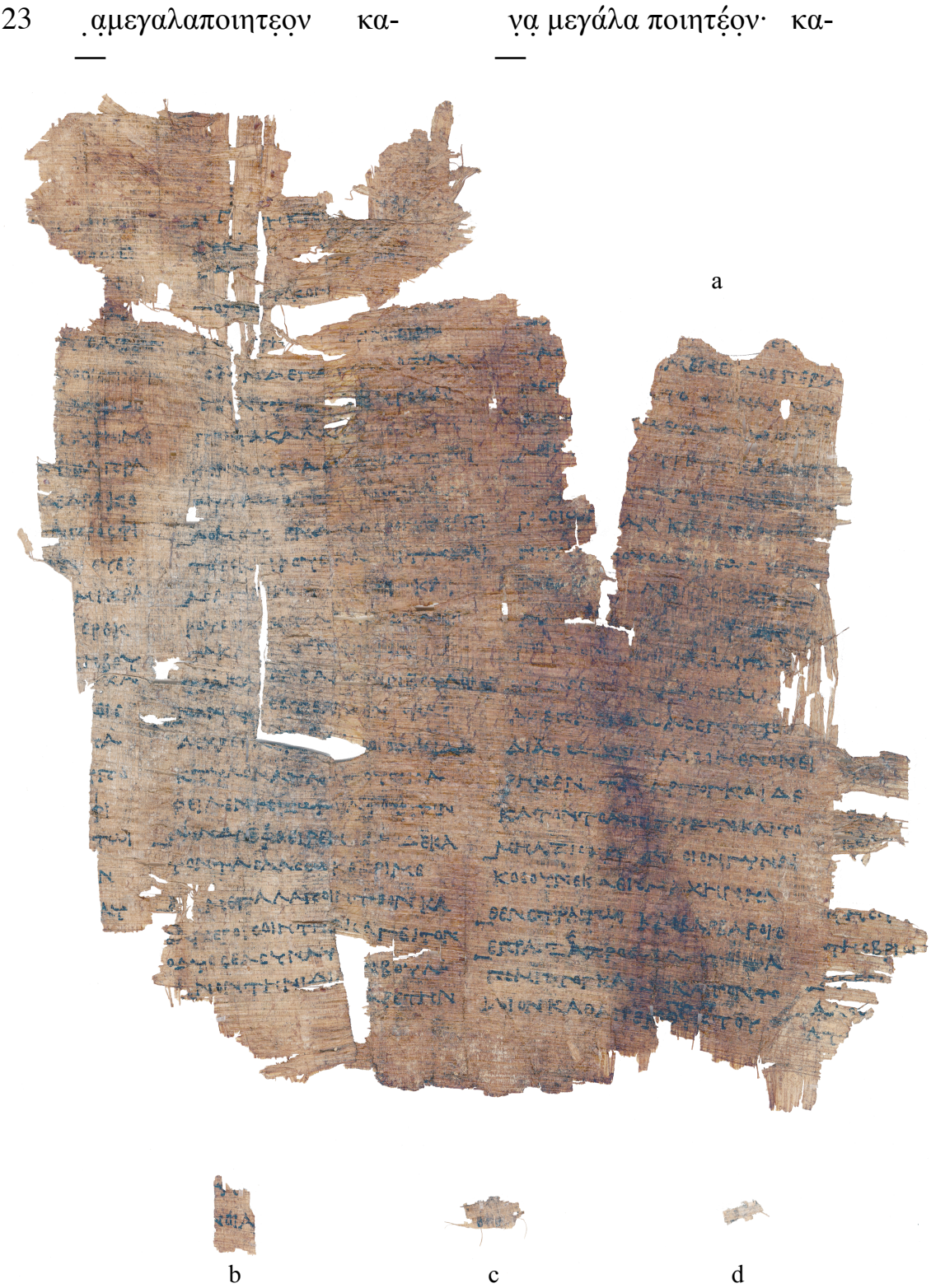

P.CtYBR inv. 5018 
24 [.] ]

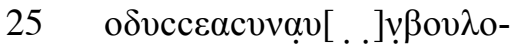

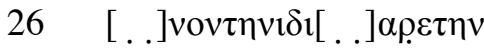

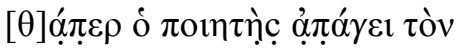

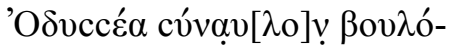

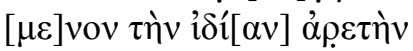

Col. iii

1 lac.

2 lac.

3 lac.

4 lac.

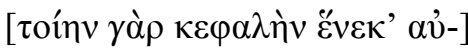

$5 \tau \omega[$

] $\varepsilon v[$

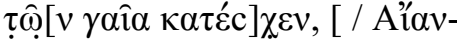

$6 \tau \alpha \mathrm{o}[$ ]$\mu \varepsilon v \varepsilon 1 \delta \circ \mathrm{oc} \pi \varepsilon \rho 1 \delta \underline{[}$

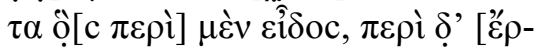

$7 \quad \gamma \varepsilon \tau[$

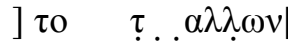

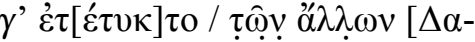

$8 v \alpha \omega[$ ] $\mu \varepsilon \tau \alpha \mu \ldots . . .[$

$9 \quad \lambda \varepsilon \underline{! ̣} \omega[.] \alpha$. $\tau \rho ! \tau o \gamma \kappa \alpha 1 \ldots \alpha[$

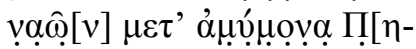

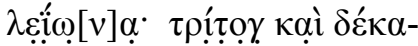

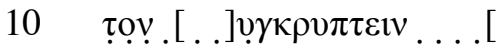

$11 \rho \alpha c i \omega \pi \alpha \nu \square \kappa \alpha \theta \alpha \pi \varepsilon \rho$. . [

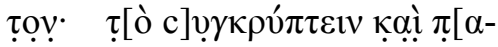
$\rho \alpha c 1 \omega \pi \hat{\alpha} v \cdot \kappa \alpha ́ \theta \alpha \pi \varepsilon \rho$ ọ $\pi \mathrm{o}[1-$

$12 \eta \eta\rceil \eta ̣[] \tau o v o \delta v c c \varepsilon \omega c$...

13 [traces c. 7] $\alpha v$ [traces

14 [traces

$15 \quad \ldots \alpha c \ldots \alpha \ldots \alpha \alpha \ln \alpha \rho \varepsilon[$

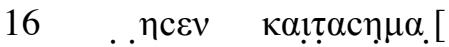

$17 \quad \alpha . \varepsilon \pi \lambda \ldots \alpha c \alpha c \varepsilon \pi . \tau \eta ฺ c[$

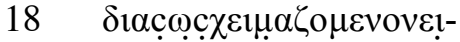

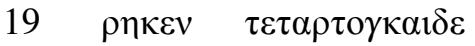

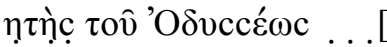

[ ] ] $] \alpha v[$

[

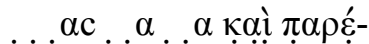

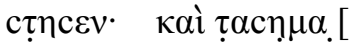

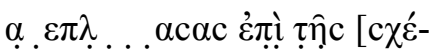
$\delta 1 \alpha c \omega c$ $\chi \varepsilon 1 \mu \alpha \zeta o ́ \mu \varepsilon v o v \varepsilon l-$

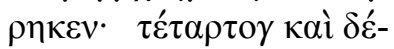

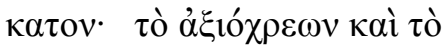

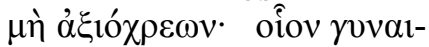

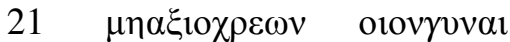

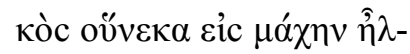

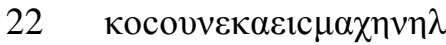

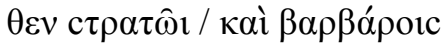

$23 \quad \theta \varepsilon v c \tau \rho \alpha \tau \omega \imath \quad \kappa \alpha 1 \beta \alpha \rho \beta \alpha \rho о г \mathrm{c}$

$24 \varepsilon \pi \rho \alpha \xi \alpha^{\prime} \varepsilon^{\prime} \pi \rho \circ \operatorname{coc} \lambda \varepsilon \varepsilon \tau \alpha \tau \alpha$

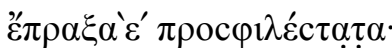

$25 \pi \varepsilon \mu \pi \tau \mathrm{\sigma} \gamma \kappa \alpha 1 \delta \varepsilon \kappa \alpha \tau о \nu \tau \mathrm{o}$

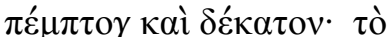

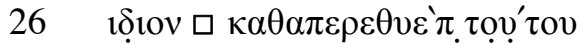




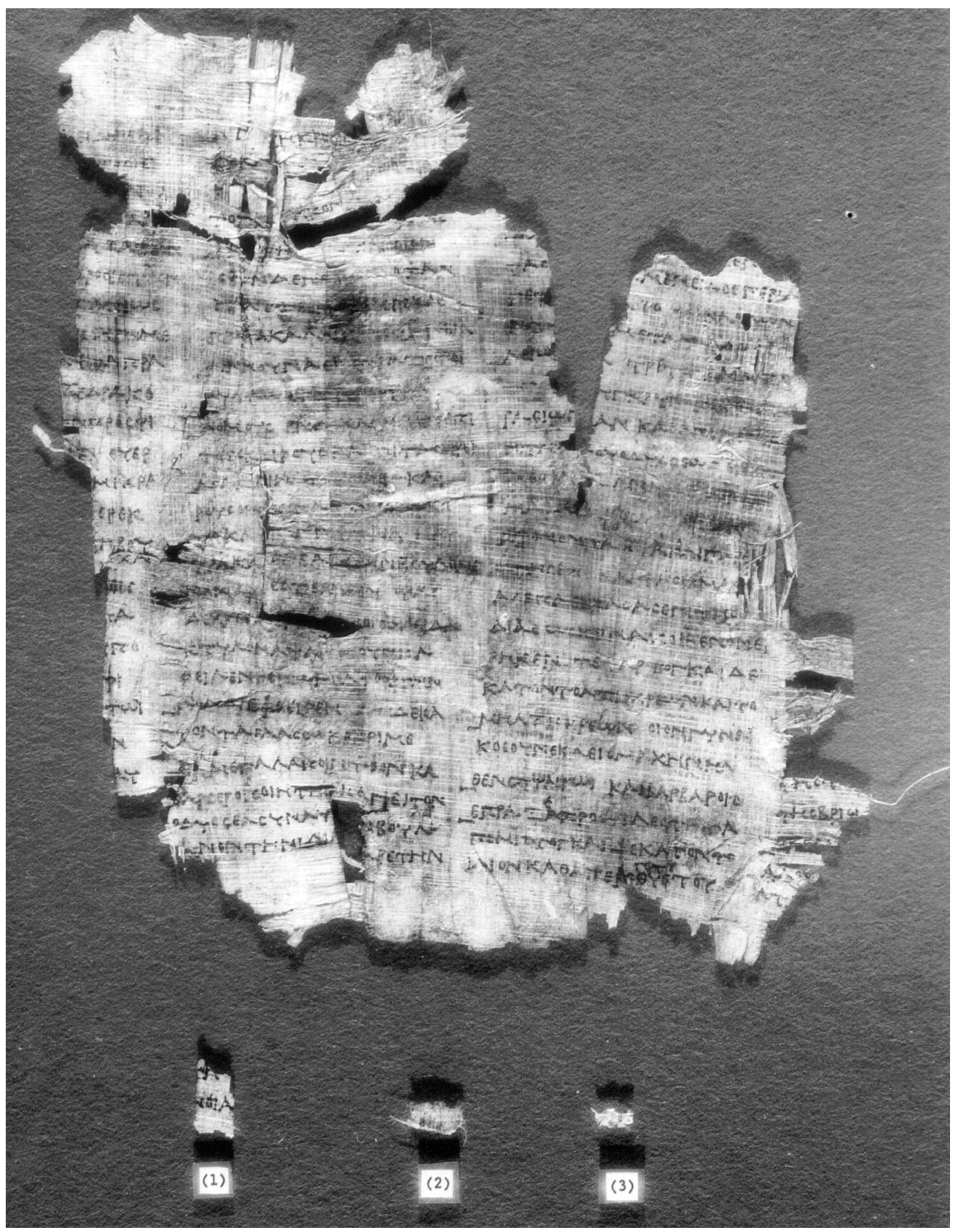

P.CtYBR inv. 5018 (infrared)

Col. iv

1-17 lac.

18 [ traces at line start]

19 lac. 


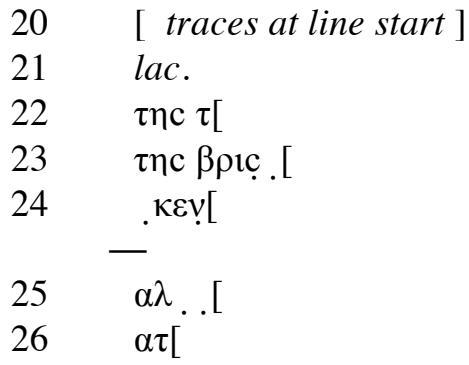

Fr. (b) [labeled (1) on the plate]

$1] .[$

1] $\operatorname{vot} \alpha[$

Fragments (c) and (d) [labeled (2) and (3) on the plate] are tiny bits with illegible traces.

\section{Translation \& Commentary}

In the notes that follow, $P J P=$ Peter J. Parsons, $T S=$ Timothy Shea, AF $=$ Alan Farnes, $D B=$ Darius Brown, $C K=$ Clinton Kinkade, $A H=$ Adrian High.

Fr. a, col. $i$, lines 1-26. Line ii.2 begins the entry for Tenth, and in columns ii and iii, there are a bit more than four entries, so we expect the first column to contain entries for Eighth, Ninth, and perhaps also the end of Seventh. None of the extant line ends match these ordinals. On the assumption that each column has about two entries, four columns (or so) of this ordinated list preceded column i.

i.11 Cf. $\pi \rho \circ c \varphi \imath \lambda \varepsilon ́ c \tau \alpha \tau \alpha$ in iii. 24.

i.10 An inflected form of the perfect participle: "doer(s)".

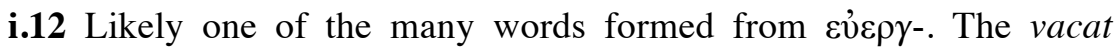
shows that this is the beginning of one of the subentries.

i.16 Horizontal breakage and subsequent distortion in the papyrus surface misleadingly makes the vertical spacing of this line appear unusual (as if an interlinear comment); it is not. 
i.21 Adscript is written here and at iii.23, which are the only two extant examples.

Lines ii.2-11. Tenth: [quoted lemma, illegible] : such as, for example if ... reputation lessened? ... first [more?] beautiful ... to [ change?] the mind always ... houses(?)

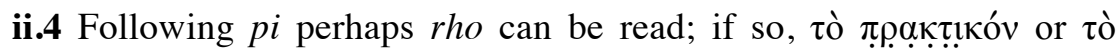

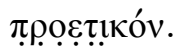

ii.5 For oîov, cf. iii.21.

ii.6-11 We expect in lines 6-11 a literary quote by way of example. Unfortunately, too little can be read to establish whether what follows is in meter; but note the Attic form $\grave{\eta} \lambda \alpha \tau \tau \omega$ [ (not, however, a certain reading).

ii.6 Traces to the left of $\delta \mathrm{o} \xi \alpha \nu$ are rounded, consistent with $\varepsilon$ or c, e.g.

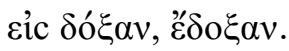

ii.8 Since $\tau \grave{\alpha}$ cannot be read at end of previous line, not an obvious phrase like $\tau \grave{\alpha} \pi \rho \hat{\omega} \tau \alpha \kappa \alpha \lambda \lambda \hat{i} \omega, \tau \grave{\alpha} \pi \rho \hat{\omega} \tau \alpha \kappa \alpha \lambda \lambda ı \tau \tau \varepsilon \hat{i} \alpha$.

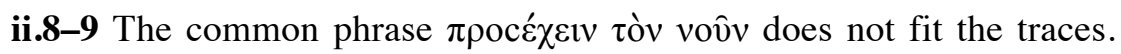

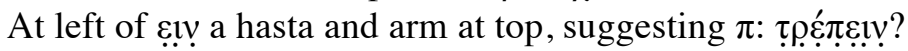

ii.9 If the format follows the example at iii.21-24, the paragraphus here signals a second quotation. The vacat is not at all certain, given the terrible state of the papyrus in this region.

ii.11 $\delta$ o $\mu$ ovc - As well as "house" and its compounds, $£ \beta \delta$ ó $\mu$ ov sible. Since this appears to be a quotation, it is worth mentioning that

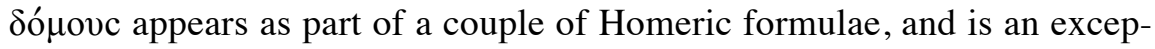
tionally common word in tragedy, appearing over 180 times in the three canonical tragedians.

Lines ii.11-21. Eleventh: "to lead towards the critical points or what is needed": as regards "to the critical points": such as, for example ... he (Agamemnon?) sent away the one (Chryses?) who wanted to deposit the ransom money ....: as regards "to lead towards what is needed": he deprived an aulete of his finger; or he destroyed the sight of a painter.

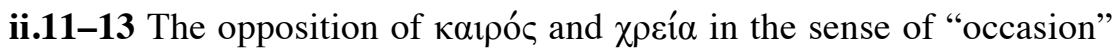
versus "need" is a favorite of Demosthenes and Aristides, among others, as a proximity search in TLG rapidly confirms. The terms are, then, 
widely used in opposition, but there are no examples with this particular phrase. For the use of "á $y \varepsilon ı$ in the sense of "lead or tend towards" see LSJ

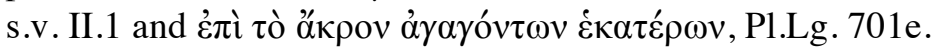

ii.14 The vacat is slight. Perhaps $\varepsilon \mu \pi \lambda[$ before the lacuna.

ii.15-17 If this is a reference to Iliad book 1, Agamemnon's rejection of Chryses is certainly is a critical turning point in the Iliad, a point I owe to PJP.

ii.15 $\lambda \underline{u-}$ - is faint and visible only on the infrared photo.

ii.17 $\alpha \pi \varepsilon c \tau \varepsilon \lambda \lambda \varepsilon \varepsilon v$ : read by TS, AF, as also $\delta \varepsilon$ at ii.18.

ii.18-20 I can find no parallels for this gruesome pair of examples. It is true that an aulete needs fingers, and a painter sight, but why these examples are chosen is perplexing.

ii.19-20 $\dot{\varepsilon} \xi \alpha \varphi \varepsilon i ̂ \lambda \varepsilon v$ : for the second letter, $p i$ cannot be excluded (nor kappa), but ksi makes the best sense.

ii.21 ộlv: read by DB.

Lines ii.21-26, iii.1-9. Twelfth: "One should make great what has been deemed the lesser": just as when the poet (Homer) brings Odysseus back home(?) as a dweller among the flocks wanting [to evince?] his distinct aretê. [After a gap of 3 lines, containing a segue to a second example, which is a quotation from the Odyssey:] "For on account of these things [i.e. Odysseus's winning the arms of Achilles over Ajax] does the earth hold such a dear head, / Ajax, who surpassed in stature and deeds / all the rest of the Danaans, second only to the blameless son of Peleus".

ii.22-23 The reading is not quite certain: the two kappas can be read only on the infra-red image. For the thought, see this comment in Athenaeus as to why Homer does not include details about food-making: $\pi \alpha \rho \varepsilon$ -

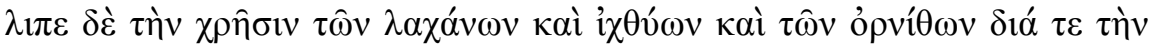

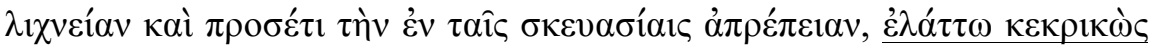
(i.e. deeming it beneath the dignity of) iं soph. 1.25 (= 49 Kaibel)).

ii.23 The use here of $\pi$ om $\tau$ çọv is same kind of instructional language typical of certain types of "problems" text. Cf. e.g. Damascius Phil., In

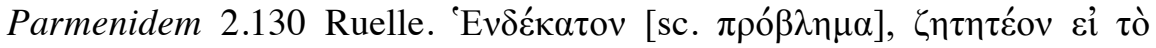

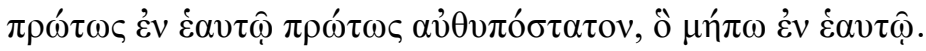




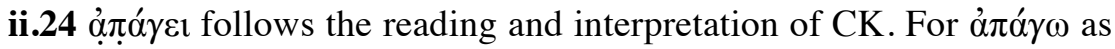

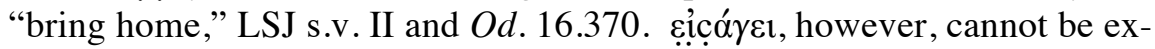
cluded, which would give the remark quite a different tenor (and one much more in keeping with the phrasing for the Eleventh). For that phra-

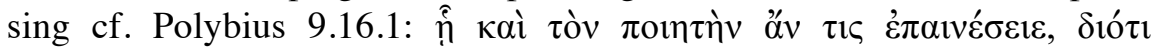

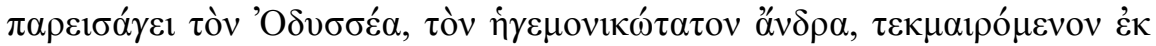

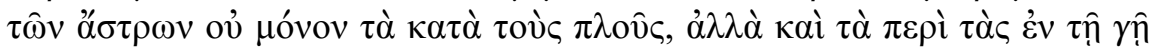
$\pi \rho \alpha \dot{\xi \varepsilon \varepsilon 1 \varsigma . ~}$

ii.25 It is difficult to decide between cuvov[ and cuv $\lambda v$ [ before the lacuna, and $n u$ after the lacuna is uncertain. The rare adjective $\sigma 0 ́ v \alpha v \lambda o \varsigma$ occurs only in tragedy and the Frogs (Eur. El. 879, Soph. Aj. 611, OT 1271, Aristoph. Ran. 212). Other possibilities seem unconvincing and fit

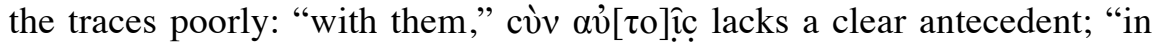
his grief," còv $\lambda v ́[\pi \eta]$, , is used as scholiastic language in Timaeus Sophista

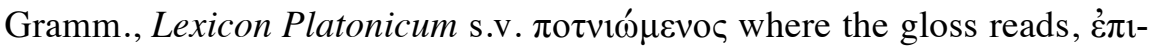

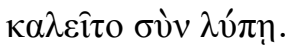

ii.26 The space in lacuna following $1 \delta \mathrm{t}$ [ could fit as many as 3-4 letters, but the two wide letters $\alpha v$ with left diagonal of the following alpha are sufficient.

ii.26 Following will be the complementary infinitive, e.g. $\dot{\pi} \pi \_\varepsilon \dot{\xi} \xi \alpha \sigma \theta \alpha 1$. The example, then, shows the poet having put his hero in a situation where he is judged by other men lesser, that is as a herdsman, and yet his greatness will soon show forth.

iii.4-9 Quotation is from the Odyssey, 11.549-551, a discovery I owe to $\mathrm{AH}$ and CK. It seems likely that line 548 was also included or paraphrased at the top of the column to give the context. The verse end is signaled by vacat without paragraphus at iii.7 (and cf. iii.23). This example too belongs to the Twelfth, and is of a man, Ajax, judged lesser in the contest for the arms of Achilles (won by Odysseus), and yet is a great man who did mighty deeds over the corpse of Patroclus. (For Ajax, it must be said, his greatness after the episode of the contest for Achilles' arms is not so readily apparent.)

iii.5 In the lacuna directly after $\kappa \alpha \tau \varepsilon ́ c] \chi \varepsilon v$ a vacat will follow, to signal the end of verse.

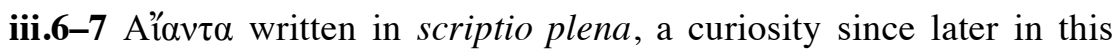
line as well as at iii.7 (' $\left.\varepsilon^{\prime} \rho \gamma^{\prime}\right)$ and iii.8 ( $\left.\mu \varepsilon \tau^{\prime}\right)$ the forms are elided. Perhaps 
to clarify since the asper follows (Aï $\alpha v \theta$ ' öc)? Scriptio plena is also written in the trimeter quoted below, at iii.22.

iii.7 Here as at iii.23, vacat is used to mark the end of the verse. The reading here of $O d .11 .550$ differs from the vulgate in having pluperfect

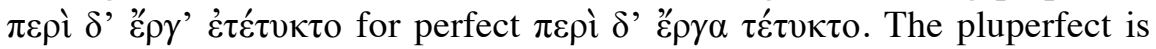
also the reading of five medieval manuscripts recorded in Ludwich's Teubner (HFTJK), ${ }^{12}$ and the pluperfect is also found in several manuscripts and testimonia for its doublet line in the Iliad, $17.279 .{ }^{13}$ No published papyri quote or contain $O d .11 .550 .{ }^{14}$ The papyri listed by West as witnesses to this area of the text for the Iliad, P.Ant. 164 (West \#501b) and P.Berol. inv. 21194+11913 (West \#636), are lacunose in this part of Il. 17.279; it is unclear whether the same is true of the two Oxy. inedit. he cites (West \#1399, 1401), but if not they contain the vulgate text.

Lines iii.9-19. Thirteenth: "to conceal and pass by in silence": just as the poet (Homer) also presented ... of Odysseus: and the poet said ... upon his raft(?), inasmuch as he was storm tossed.

iii.9 Assimilation of final nu to gamma before the velar, as commonly in papyri; so also at iii.19, iii.25.

iii.11 Only ink traces are left at end of the line. These are consistent with $\mathrm{o} \pi \mathrm{o}[\mathrm{l}$, but the restoration remains conjectural.

iii.12 $\pi \tau \eta c$ is also possible, e.g. $\kappa \rho v-\pi \tau \eta c, \kappa \alpha \lambda v-\pi \tau \eta c$. Faint traces fol-

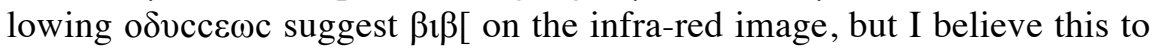
be a chimaera.

iii.15 $\pi \alpha \rho \varepsilon ́ \sigma \tau \eta \sigma \varepsilon v$ in the Homeric scholia frequently means to present a scene/emotion/character to the reader (a point I owe to PJP). Cf. sch. vet. in Il. ad 1.4, 342b, 4.141c, 5.314, 734a2, etc. The reading, however, remains uncertain: $\gamma \alpha \rho$ for $\pi \alpha \rho$ cannot be excluded here, and we might expect a couple or few more letters in lacuna at the right.

${ }^{12}$ Arthur Ludwich, Homeri Carmina (Leipzig 1889-1902) ad loc.; not mentioned in the app. crit. of von der Mühll's 1984 Teubner.

${ }^{13}$ Martin L. West, Homeri Ilias (Stuttgart 2000) ad loc.

${ }^{14}$ The forthcoming Odyssey Teubner by Martin West will provide readings for several hundred unpublished Homeric papyri, but is as yet unavailable. 
iii.16 $\sigma \eta^{\prime} \mu \alpha \tau \alpha$ is the usual language of Od. scholia for the scar and bed that reveal who Odysseus is. But the remains at the right edge do not encourage $\tau \grave{\alpha}$ cṇ́ $\mu \alpha \tau[\alpha$, nor is it easy to see how that would fit in below.

iii.17 At front, alpha could be lambda or delta, and the lambda in $\varepsilon \pi \lambda$ could be alpha; other letters read in the sequence $\alpha . \varepsilon \pi \lambda \ldots \alpha c \alpha c$ are clear. The infrared photo suggests epsilon to follow lambda. But wording and

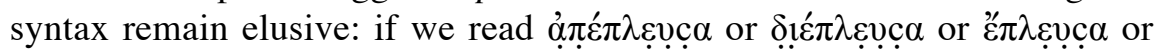

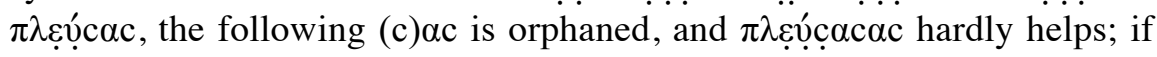
we read from the smudges $\pi \alpha c \alpha c$, it is hard to know what to do with what comes before (what would e.g. "̈ $\pi \lambda \varepsilon \underline{1} \pi$ $\alpha \hat{\alpha} \mathrm{c} \alpha \mathrm{c}$ refer to?). Note that there are only a few letters between $\tau \alpha c \eta \mu \alpha$ and whatever this line reads. Following a different line of attack, one could read the tragic word áḉ $\pi \tau \underline{c}$ ("unholy") at right, and a possibility for the sequence $\pi \lambda \ldots \alpha \mathrm{c}$ is (again, from the infrared) $\pi \lambda \varepsilon_{\xi}^{\prime} \xi \alpha c$. The word ending in $-\delta 1 \alpha \mathrm{c}$ is then released to any number of possibilities (ij $\mu \omega \delta \delta^{\prime} \alpha \varsigma, \chi \rho \eta \sigma \mu \omega \delta \delta^{\prime} \alpha c, \tau \rho \alpha \gamma \omega 1 \delta i^{\prime} \alpha c, \delta v \sigma \omega \delta \delta^{\prime} \alpha c$, even $\kappa \alpha \rho \delta \delta^{\prime} \alpha c$, i isíac), but it is hard to see how any of this fits together sensibly. In short, there seems enough legible here to sort out the puzzle, but I confess defeat.

iii.17 A clumsy broad nu is also possible for $\pi !$, i.e. one could read $\varepsilon v$. But if $\dot{\varepsilon} \pi \grave{\imath} \tau \hat{\imath} \mathrm{c} . . . \delta \mathrm{t} \alpha \mathrm{c}$ is right the context seems strongly to suggest Odys-

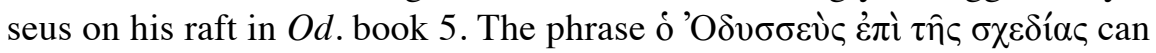

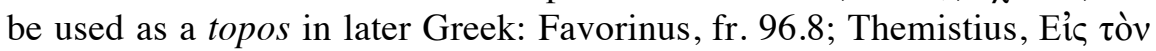

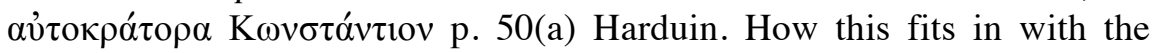
theme of concealment and silence is, however, unclear.

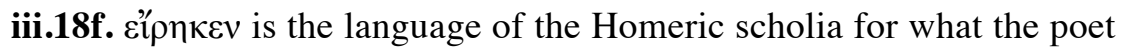
says (PJP). Cf. sch. vet. in Il. ad 1.467a, 497b1, 2.788, 809, 813-4, 816, etc.

Lines iii. 19-24. Fourteenth: "What is worthy and not worthy": just as, for example, "For the sake of a woman he came to fight with an army" I "and he worked things most pleasing to the barbarians".

iii.21-24 These lines will scan as trimeters, thus apparently a quote from one or two lost tragedies. The two lines are separated by space, as with the running lines from the Odyssey (see iii.7), but also have a paragraphus separating them. The paragraphus, I believe, is meant to clarify that the trimeters are from different contexts, perhaps different plays.

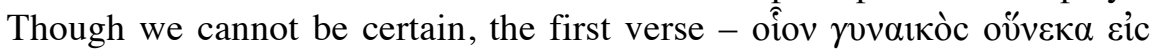




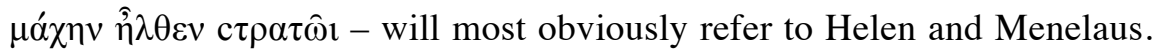
Indeed, the verse seems to be an intertext for a line in Euripides' Orestes,

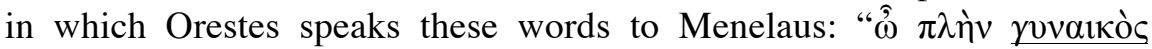

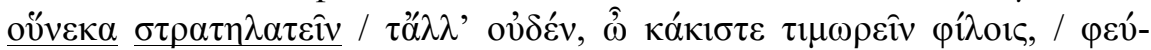

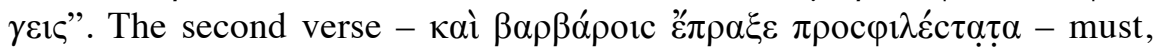
however, have a different subject (and thus the paragraphus), since surely Menelaus did not accomplish things pleasing to the barabarians. The poetic reference in that case, then, seems not to be from the Trojan cycle. In the exemplum, fighting for the sake of a woman is what is "worthy" and doing things that please the barbarians (one thinks of various medizing traitors) what is "not worthy". That fighting for the sake of Helen is "worthy" is traditional, but also interesting, since the tragedies that come down to us explore so thoroughly the moral ambivalence of the expedition against Troy.

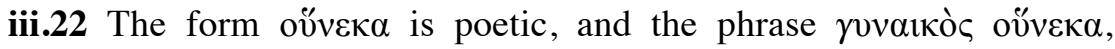
usually with reference to Helen, occurs repeatedly in extant tragedy (and only there): Aeschylus, Ag. 823, Sophocles, Ant. 649, Euripides Med. 593, Herc. 1308, Troiades 372, 865, Or. 717, Iph.Aul. 1393. Note that scriptio plena is used again here, as it was in the Homeric quote at iii.6 (but not later in that line, or at iii.7 and iii.8).

iii.24 ' $\varepsilon \rho \alpha \xi \alpha$ ' $\varepsilon$ ': There is no expungement dot over alpha, so it is not clear whether the scribe intends a correction or the recording of a variant reading.

Lines iii.25-26. Fifteenth. "what is distinctive": just as he sacrificed / raged....

iii.26 The ink that survives would also allow the reading $\tau$ ò "I $\mid \lambda$ เov, but that does not fit with the other lemmata. The reference here seems to be to what is particular or individual or characteristic, or perhaps what is in someone's interest. In philosophical treatises from Aristotle onward, ‘ $\delta$ ioc is commonly used in a technical sense for the characteristic property or distinguishing feature (of a species, sim.): LSJ s.v. IV .

iii.26 The word division $\dot{\varepsilon} \theta \dot{v} \varepsilon \tau$ o $\dot{v}$ - is also possible. The correction or comment added above $\varepsilon \theta v \varepsilon$ is difficult. Could the reading be $\pi \varepsilon \tau o v$, inten-

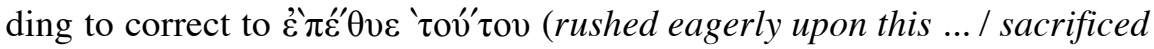
besides ...)? Could Agamemnon's sacrifice of his daughter Iphigeneia be in view? 
Column iv will contain the rest of the remarks on the "fifteenth" and possibly continue with the "sixteenth" and "seventeenth". None of the line beginnings match these ordinals.

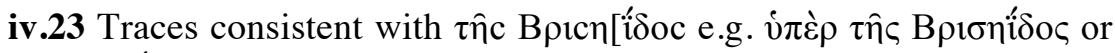

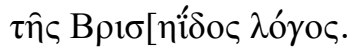

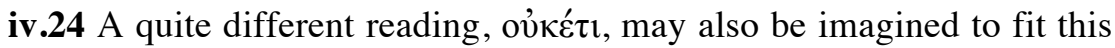
distorted area of the papyrus, as CK suggests. ${ }^{15}$

\footnotetext{
${ }^{15}$ I here record my thanks to the students in two courses in Literary Papyrology at Duke in 2012 and 2015 who took on this difficult papyrus, and thereby helped to confirm that some of my more hesitant readings had a reality. Among those, I single out Clinton Kinkade and Adrian High, who contributed in substantial ways (see notes) to the transcription. Finally, I am deeply grateful to Robert G. Babcock, who first drew my attention to this papyrus, kindly shared the first views of the piece, and encouraged me to work on it; and to Peter J. Parsons, who shared valuable initial thoughts and reactions to an early draft.
} 